\title{
Designing and constructing corrugated glass facades
}

\author{
Rob Nijsse ${ }^{a, *}$ and Ronald Wenting ${ }^{\mathrm{b}}$ \\ a University of Delft (NL) \& Consulting Engineer, ABT, Arnhem, The Netherlands \\ ${ }^{\mathrm{b}}$ Structural Engineer, ABT, Arnhem, The Netherlands
}

Submitted 2 July 2014

Accepted 20 November 2014

\begin{abstract}
Flat glass panels are in use since the time of the Roman Empire. In the ruins of the city of Pompeii, destroyed by the Vulcan Vesuvius in 79 DC, a glass panel in a bronze frame of $300 \times 600 \mathrm{~mm}$ was found. In this article we describe a mayor improvement in the structural behaviour of glass panels by making the glass curved, or more accurately, corrugated. Both the in- and out-plane loading meet far more resistance against deformation, and the corrugated glass panels have a largely increased bearing capacity with the same thickness of glass the flat panel has. Also architecturally the appearance of a corrugated glass panel in facades is far more appealing.
\end{abstract}

Keywords: Glass, corrugated glass, facade, innovation, structural engineering

\section{Introduction}

Glass is becoming a more and more reliable structural material. However strange this may seem, your wine glass breaks when the wind tilts it over and a football kicked against a window will break it. However, thanks to the laminating and toughening of glass panels, we are able to make strong, safe and resilient structures out of glass. In this way we do keep the most prominent feature of glass: its transparency. So we, the structural engineers, are able to realise the ultimate dream of each architect to design a building or spaces without the annoying view blocking presence of walls, beams, floors and columns. In accordance with the 'Zeitgeist' architects have to make their designs, like all other aspects in modern society, 'transparent'. Glass structures therefore add an extra value to the governing principles of modern society. Looking back it will be about thirty years ago that the first steps were set to turn each structural element of a building into a (safe) all glass one. A little steel in the form of bolts, plates and cables to make connections or to provide extra stiffness is sometimes necessary, but on the whole we now are able to make all characteristic structural elements like beams, columns, floors, roofs and facades out of (structural) glass. Furthermore, in this article a new innovative method to create large wind load carrying glass facades is presented. Without structural elements like steel beams and columns and using small glass thicknesses, a method has been developed to achieve this.

\footnotetext{
${ }^{*}$ Corresponding author: Rob Nijsse, University of Delft (NL) \& Consulting Engineer, ABT, Arnhem, The Netherlands. E-mail: r.nijsse@tudelft.nl.
} 


\section{The working of corrugated glass}

When we take a flat piece of paper in our hands it is weak, and slack. However, if you fold this piece of paper a few times the structural behaviour changes from weak to strong and from slack to stiff. Luckily enough the glass manufacturing firms are more and more capable to create folded, or better, corrugated glass. Therefore we have started to create glass facades in corrugated glass. Two well-known buildings incorporate corrugated glass in their facades: the Casa da Música in Porto, Portugal (architect OMA) and The Museum aan de Stroom (MAS) in Antwerp, Belgium (architect Neutelings Riedijk).

\section{Casa da Musica in Porto (Portugal)}

In 1997 the Office for Metropolitan Architecture (OMA) headed by the Dutch architect Rem Koolhaas won a competition for the Cultural Centre of Porto in Portugal. The architects had designed a rather surprisingly shaped box of white concrete that should contain the various cultural activities to be housed in it. In the white concrete box large, very large, openings were made to let the daylight enter the building and to give the visitors of the building an astonishing view over the town of Porto.

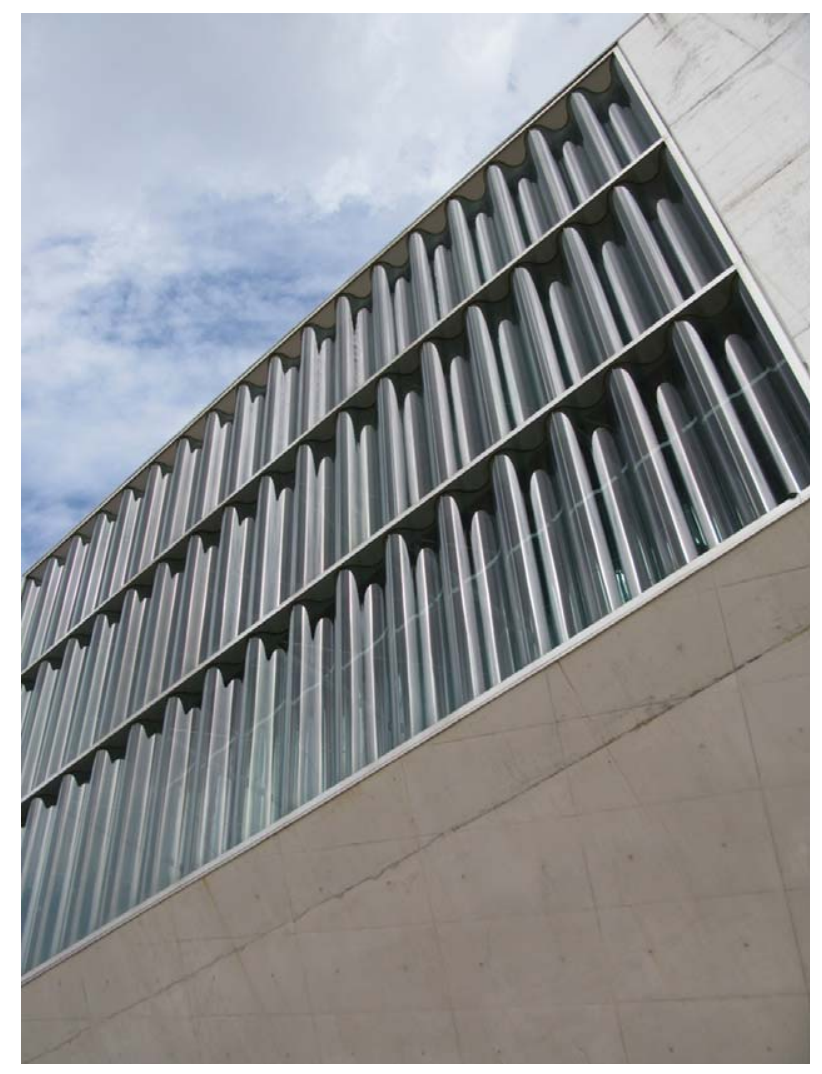

Fig. 1. The big window in the Casa da Musica in Porto. 
Our consulting firm ABT was asked to make a proposal for the facade of the large windows, the biggest one to be measured 25 by 12 meter, using as much glass as possible and, preferably, no steel (Fig. 1). We tried all kinds of slender cable-stayed structures, but these remained unacceptable for the architect: "I don't want all that steel spaghetti around the glass". As we tried to figure our way out of this 'mission impossible' we found a publication of the Spanish firm Cricursa, telling about a large corrugated glass panel wall they made for the interior of a shop. Putting two and two together we made a proposal for a large window made out of large corrugated glass panels stacked on top of each other. Due to the then valid production restrictions we could make 4.5-meter high, corrugated glass panels, so the total height of 12 meter was divided in three parts, which luckily enough fitted in with the position of the floors of the foyer/circulation space that sometimes passed through the voids. The architects immediately embraced the proposal. As we later learned, especially the contrast between the flat, smooth surface of the white concrete and the corrugated, shining, brilliant surface of the glass facade was appealing. The structural effect of a corrugated panel is clear: it can take up much more wind load than a flat one of the same thickness. Therefore a minimal number of steel cables, columns and beams is necessary to support the glass. These steel beams are part of the horizontal steel trusses and have facilities for both mounting and adjusting the tolerances of the corrugated glass panels (Fig. 2).

The architect wanted to have daylight in the big Auditorium, a feature rarely seen in theatres. So we had to make two walls of corrugated glass, one wall on the outside, to take up the wind load and to provide water tightness and insulation, and one wall on the inside dividing the theatre from the foyer/circulation area. It might be suspected that the sound quality inside the theatre would be affected by the presence of glass, a hard reflecting material. Study of the acoustical adviser learned that due to the corrugated surface a very effective dispersion of the sound could be obtained, and the effect of double glass wall resulted in a more then enough sound level reduction from inside to outside and the other way around.

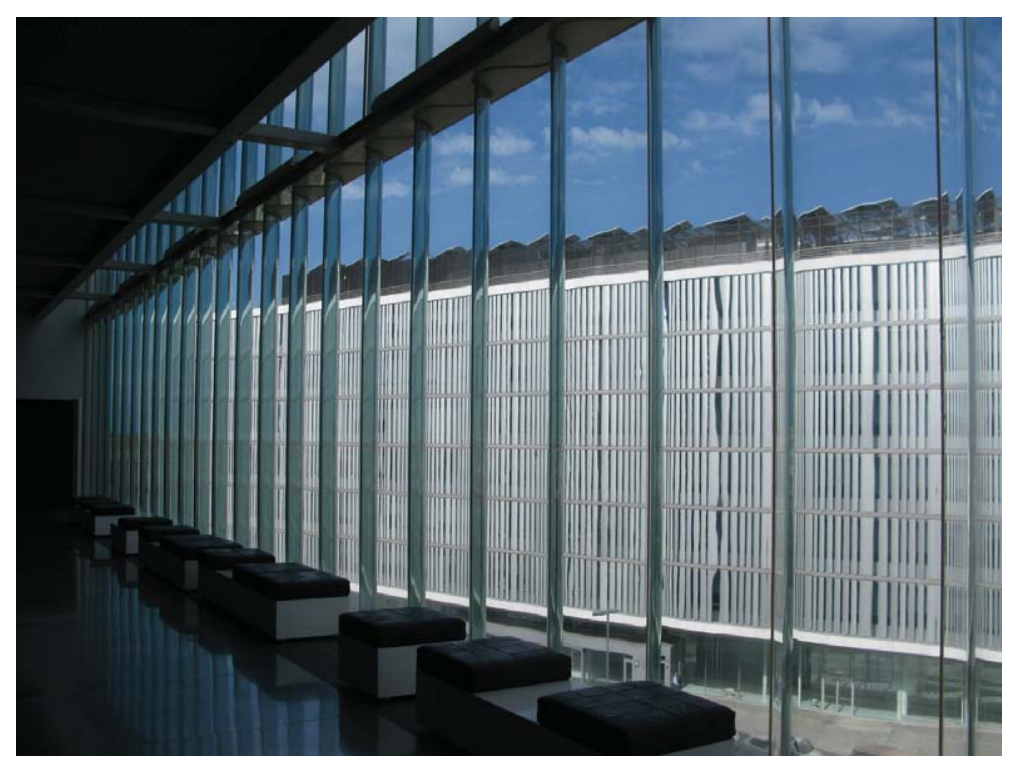

Fig. 2. The view through the corrugated glass panels of the Casa da Musica in Porto. 


\section{Museum aan de Stroom (MAS) in Antwerp (Belgium)}

A desire to improve the quality/atmosphere of the old disused harbour quarter directly situated near the historic city centre of Antwerp, led to plans to develop a new large museum. This new museum was meant to incorporate several museums in Antwerp, housing objects diverting from historic to folkloric and modern art. In 2000 an architectural competition was held for five selected architects. The competition for the 12.000-m2 floor space building was won by Neutelings Riedijk Architecten, with ABT as structural advisor.

The design of Willem Jan Neutelings was simple but beautiful. By housing each category of the museums in a concrete flat box, security, fire proofing and optimal climate control was possible. By placing the in total eight boxes of the museums on top of each other and putting an entrance layer on the ground floor and a restaurant on top, a sixty meter high building was created. The stroke of genius on the part of the architect was that by twisting each layer of this stack of boxes over 90 degrees a spiral walkway connecting the various museum boxes was made. Another result of this twisting is that the visitors, while climbing up, also have beautiful views over the city of Antwerp, each time from a different direction (Fig. 3).

Although the structure of the MAS itself is interesting, the glass facades filling in the space between the various museum boxes are the subject of this paper. The height of this facade at the corner areas is two times the story height of a museum box, being 5,5 meter, so an 11 meter high glass facade results. Of course the architect desired only glass as facade. From the experiences with the Casa da Música project, which was carried out at that time, we were able to propose corrugated glass for this project as well. The special challenge of the MAS project was, that here in one go a facade of 11 meter had to be realised. Corrugated glass elements of 11 meter long are an illusion; they cannot be made in the furnaces and the glass industry has a 6- meter length limitation due to production and transport restrictions. The Italian glass provider

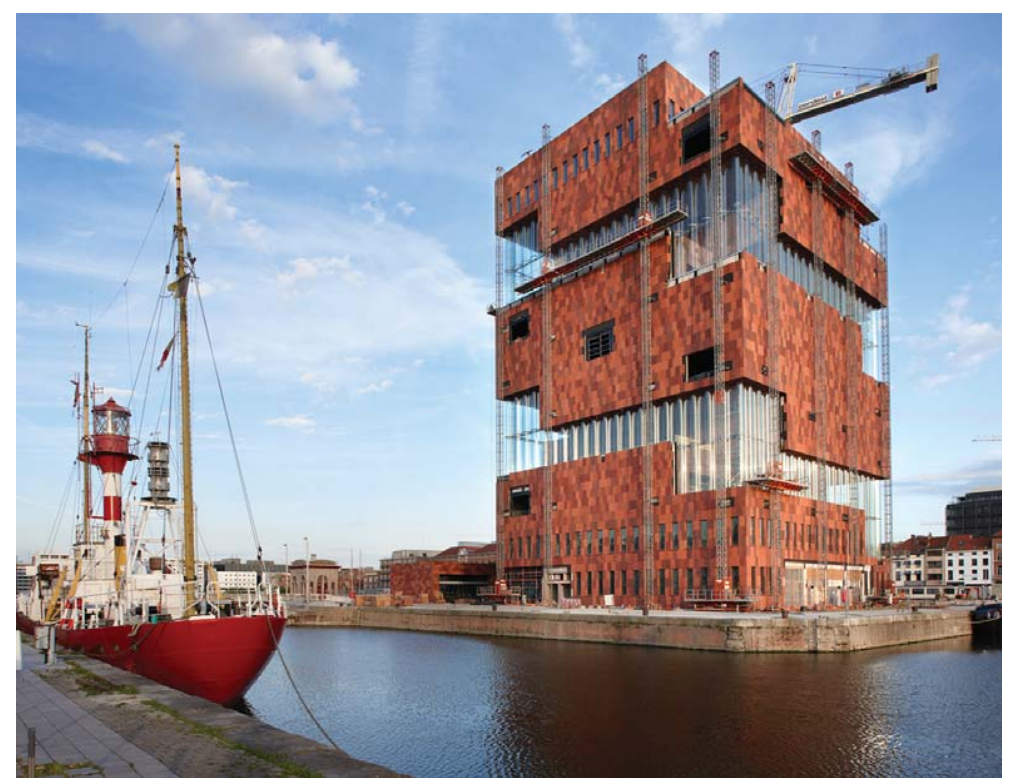

Fig. 3. The building of the MAS on the 'Eilandje' (=small island) in the old harbour of Antwerp (image courtesy of OMA; photography by Philippe Ruault). 


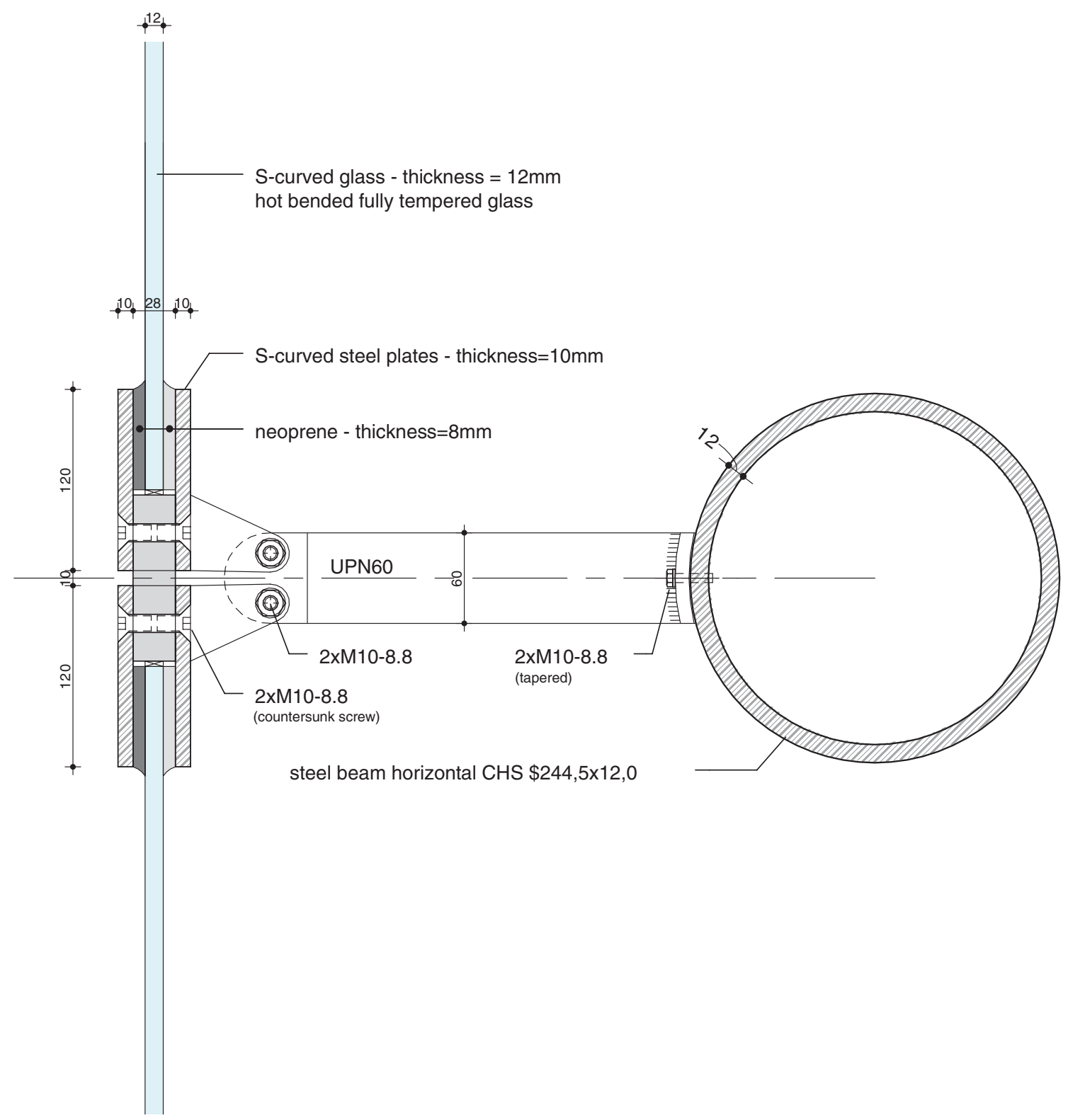

Fig. 4. The horizontal, intermediate connecting middle detail of the 11-meter high corrugated glass facade of the MAS.

Sunglass was able to produce the desired shape of corrugated glass in the length of 5,5 meter. So we divided the 11 meter in two parts of 5,5 meter. This implied a 'support' halfway that, of course had to be as slender as possible to not undo the desired overall transparency (and view) of the facade. This problem was solved by connecting the two corners of the adjacent concrete blocks with a steel tube as intermediate support halfway. This tube is only meant to carry the wind load and serve as a horizontal support for the facade; the weight of the facade itself is carried by simply stacking the corrugated glass panels on top of each other. So for wind load the corrugated glass panel behaves structurally as a plate on two lines of 
support, spanning 5,5 meter. Another serious critical point of the production of corrugated glass is the exactness in which the panel's dimensions can be made. Preferably we would like all elements to have the same width, the same length and the same curvatures. Since it is a production process, that produces the elements one by one, exact uniformity is an illusion. It is our experience from the Porto and the Antwerp projects that tolerances of $\pm 2 \mathrm{~mm}$ are possible. Regarding the shape of the corrugated glass panel the choice is made by the designers what curvature the glass panels should have. This is an architectural and visual issue but it may have large implications on the structural behaviour and the building costs. In general the recommendation can be made to choose symmetric elements. The manufacturing process does not require this, although it has other restrictions to the shape. But this is dealt with by following a simple rule that states: if you can fold the desired corrugated shape out of piece of paper, the glass industry can make it. The demand mentioned here is a consequence of structural restrictions. It does not rule out asymmetric cross-sections, but one has to be aware that a-symmetric profiles mean extra stresses in the material glass and this may mount up to $25 \%$ ! The reason for this is that there is different behaviour in stiffness when a concave element (hollow shape) or a convex element (rounded shape) is loaded. The convex shape is weaker and deforms easier.

The fact that the glass panels are merely standing on each other led to some discussion. One: are the stresses called up by this stacking acceptable? Two: if a lower panel breaks, of whatever cause, will the top one not come down? And three: can the broken panel be replaced? Answer to question one: the level of normal stresses (compression) in the glass varies from $2 \mathrm{~N} / \mathrm{mm}^{2}$ (concentrated points of support) to $0,2 \mathrm{~N} / \mathrm{mm}^{2}$ (uniform support), very acceptable; values certainly for compression, one of the strong features of the material glass. Answer to the second question: concerning the possible breakage of the lower panel: if one simply let the panels stand on top of each other, this will be a problem. Also in combination with question three: the replacement, this is a critical aspect. Therefore it was decided to add a steel horizontal beam that was strong enough to carry the weight of the top one, when the lower panel collapsed, but slender enough to be incorporated.

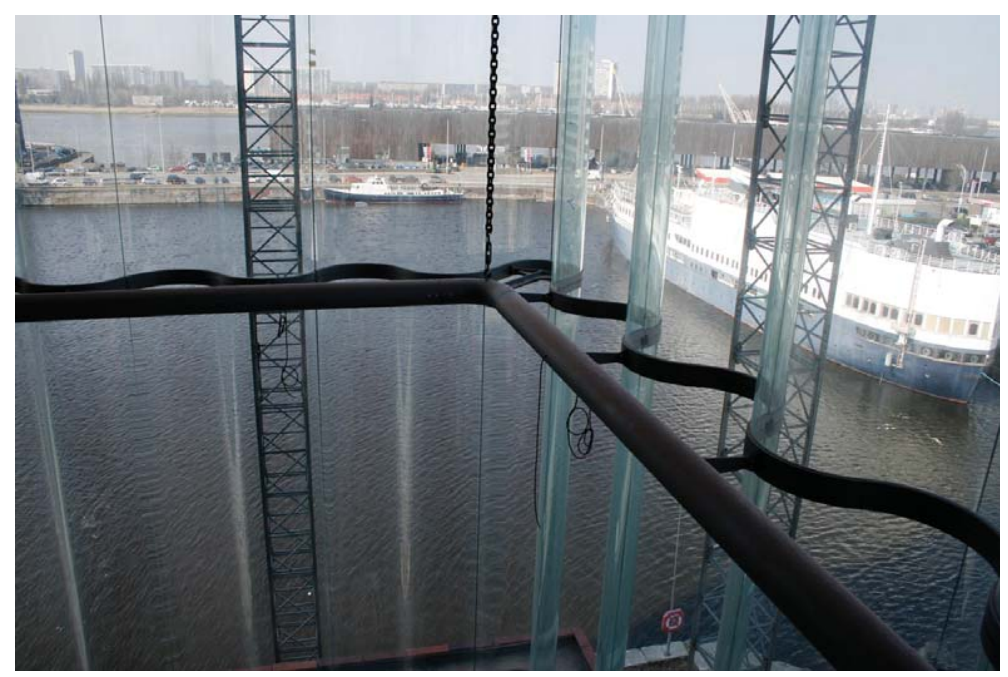

Fig. 5. The view through the 11-meter high corrugated glass façade in Antwerp (image courtesy of OMA; photography by Philippe Ruault). 
As one can see in Fig. 4, steel plates follow the shape of the corrugated glass in order to make a good detail, easy to maintain and assemble. The waterproofing is guaranteed by silicone joints at both the in- and the outside. The connecting detail at the underside and the upper side was worked out with the same principle. Beauty is in the details, so it is important to perfect them; also we have to have an open eye for maintenance and cleaning.

Up till now we have been talking about 'a' corrugated glass panel. But how do you choose the 'corrugateness' of a corrugated panel? During this discussion with the architect we made some reconnaissance calculations that learned that from a ratio of 1 to 20 of the wave-height to span, the structural effect of the corrugateness was evident. So we stuck to that but the architect reacted by doubling this value with the argument that the view distortional effect from a distance is less and that people could stand 'in' a wave of glass close to the facade. The distortion close to the glass is also minimal (Fig. 5). All this implied that our 'wave-height' is now $2 \times 300$ is $600 \mathrm{~mm}$. The elements were chosen to have the shape of a lying $\mathrm{S}$, with a width of $1800 \mathrm{~mm}$. We calculated a required glass thickness of $12 \mathrm{~mm}$ float glass.

\section{Two more corrugated glass projects under construction}

As already mentioned two more projects of architect OMA are under construction. The almost finished one is the University Library of Doha, Qatar. A square plan building with diamond shaped facades, roughly about 80 meters wide and in the centre the biggest height: 17 meter. Here the corrugated glass is chosen by the architects for, visually, giving water' in the 'desert' to the building. Because of the climate it is not a 'sensible' choice to make a big glass. Therefore corrugated insulated glass units had to be produced (to keep the cold inside). The Cricursa firm from Barcelona, Spain took up and solved this manufacturing challenge (Fig. 6). Furthermore a fritting pattern of ceramic dots to the surface of the glass provided a first line of reflection for direct sunlight entering the library. Also the glare issue was tackled in this way.

The second building under construction is the TPAC, the Taipei Performing Arts Centre in Taipei, Taiwan. A central cubically shaped building is cladded on three facade sides by a corrugated glass façade (Fig. 7). The fourth facade side is cladded by perforated metal sheet panels. The three theatres that are 'hanging' to the cubic volume are cladded with a, as jointless as possible, aluminium panelling The corrugated glass goes to a maximum-stacked height of 25 meter, one step onward from the 17-meter height at Doha. Architects like to push boundaries; engineers and manufacturers have to respond to this wish. The corrugated glass comes from China and is fabricated and installed under the supervision of the firm CDC, Curtain wall Design and Construction, Inc., from China. Special challenge of building a public building in Taiwan is the fact enormous wind loads (typhoon) of about three times as much as in Europa had to be calculated. The corrugated glass shape proved to be an economic answer in this. Another challenge was the demand by the authorities to make sure that the glass would not break during an earthquake. Besides laminated glass, ABT designed connecting details that allow movement of the building's structural frame during an earthquake.

\section{Future applications for corrugated glass panels}

Now it is possible to make facades out of corrugated glass, even in laminated glass and insulated glass units, we may think about another possible use in the construction of buildings. 


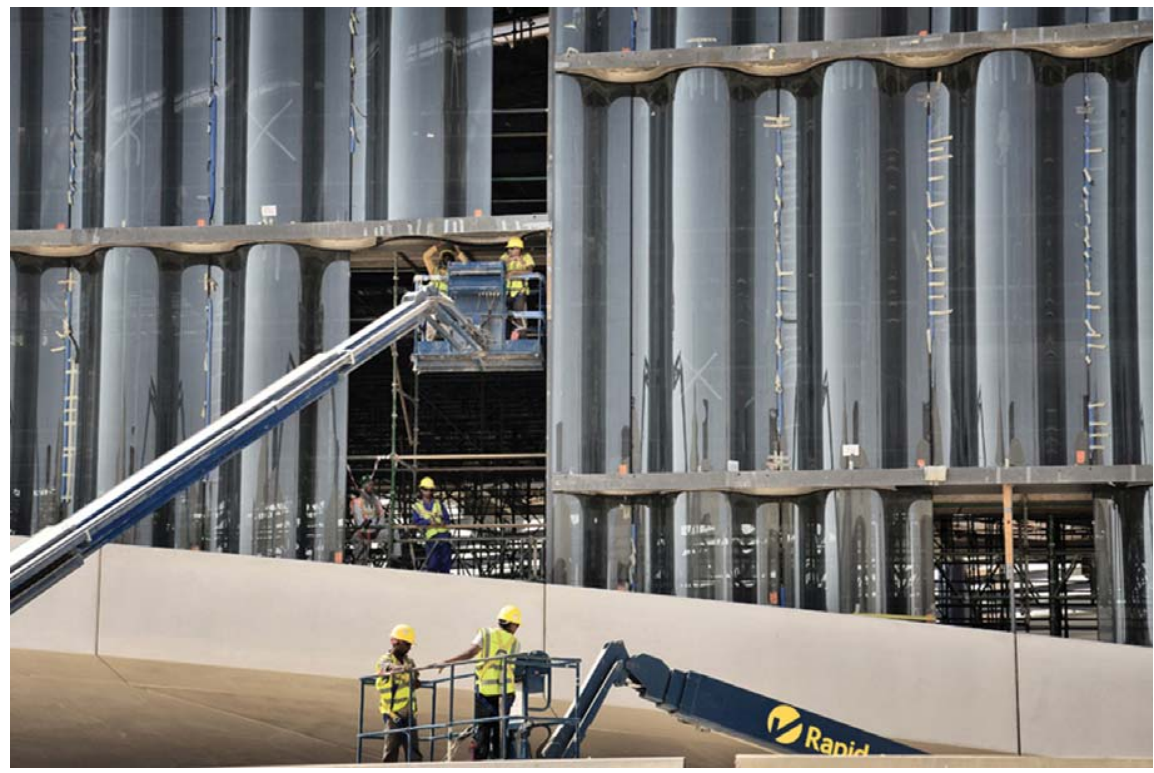

Fig. 6. The diamond shaped corrugated glass facade (east) of the University Library in Doha, Qatar under construction.

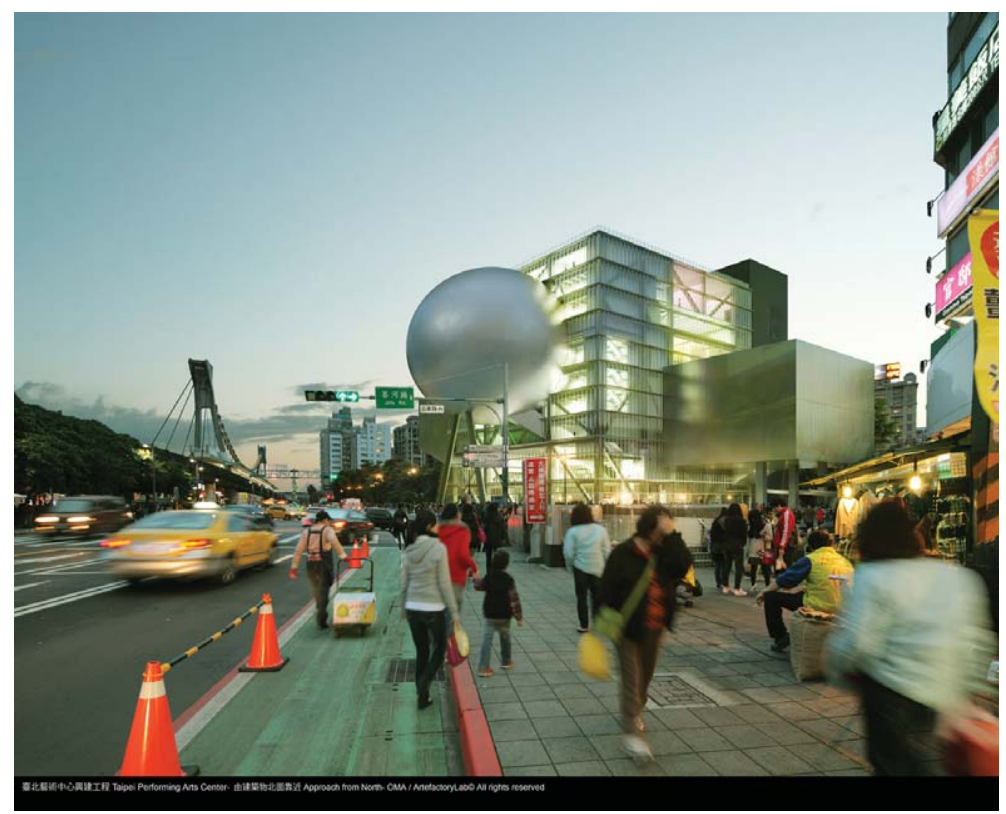

Fig. 7. TPAC building, perspective approach from north (image courtesy of OMA; photography by Philippe Ruault).

1. Roofs. Why not? If the improved static behaviour (compared to flat glass panels) works for the windload; why not for the dead load or the snow load when it is placed horizontally, as a roof? The transparency combined with the natural waterthightness of glass makes it a very interesting roofing material. Of course sun shading is an important issue that has to be taken care of. 
2. Walls. Flat glass panels have a very unfavourable structural behaviour concerning axial loads. Buckling or plying will occur very quickly at already low normal-stress levels. For corrugated glass this is far better. A simple test with a piece of folded paper to act like a wall demonstrates the enormous rise in bearing capacity compared to the same piece of paper as a flat panel. Also from a stability point of view: a flat panel tilts over easily while a corrugated panel stands firmly, so a choice for a corrugated panel is obvious. We did make a proposal for a load carrying, corrugated and insulated glass wall as a perimeter to a villa designed by the Dutch architects MVRDV. The German firm of Finiglas was able to make the corrugated insulated glass units in a safe and even cost-attractive way: $120 \%$ if compared to a standard brick wall with large glass windows.

\section{Conclusions}

Corrugated glass represents a more then $1000 \%$ increase in bearing capacity for loads applied out of plane of the glass. For loads in-plane of the glass, the buckling and plying resistances increase also dramatically. When we realise that the glass thickness does not change at all, it is clear that we have a very sustainable application of glass. Architects have pointed out to us that the water-like appearance of corrugated glass is positively better than the dull shimmering of flat glass, leading to a more lively and therefore beautiful facade.

\section{References}

El Croquis 131/132. (2006). OMA Rem Koolhaas. Madrid, Spain: Croquis editorial. Knaack, U. (1998). Konstruktives Glasbau. Köln, Germany: Verlag Rudolf Müller. Neutelings, W. J., et al. (2004). At Work! Rotterdam, The Netherlands: 010 Publishers. Nijsse, R. (2003). Structural Glass. Basel, Switzerland: Birkhäuser. 